\title{
Prevalence of Post-Traumatic Stress Disorder and Its Impact on Job Satisfac- tion and Perceived Job Performance: Evidence from Afghanistan
}

\author{
Abdul Waheed ${ }^{1}$, Shabana Gul ${ }^{2}$,Muhammad Khan Riaz ${ }^{3}$, Muhammad Naeem*4, \\ 1,2,4 Institute of Management Sciences, Peshawar, Pakistan \\ ${ }^{3}$ COMSATS University, Attock, Pakistan
}

\begin{abstract}
The study investigated the prevalence of Post-Traumatic Stress Disorder PTSDand its impact on job satisfaction and perceived job performance in faculty members of private universities in Kabul, Afghanistan. The country has been affected by wars since 1979 USSR invasion, then civil war and now by ongoing war on terror. Utilizing questionnaires as data collection tool, 126 complete responses were received from six universities. Using a threshold score with help from literature, it was found out that in $65.08 \%$ respondents PTSD prevailed. The results showed that PTSD has significant negative impacts on job satisfaction and perceived job performance. Conclusively, the study suggests some recommendations for policy makers, especially the concerned institutions of the government of Afghanistan and the management of universities. These recommendations would help the concerned authorities to come up with certain solution plans, policies and strategies to cope up with the problem and reduce the level of PTSD and enhanced the psychological wellbeing of the faculty. This in return would help them attract some experienced professionals from across the globe and retain the current pool of talent for providing quality education to the citizens of Afghanistan which can help in paving the way to an educated and developed Afghanistan. Facilitating their safety and security can lead to a safe and secure mind without PTSD that can lead to increased productivity, loyalty and commitment which ultimately contribute to achieving organizational short and long run goals.

Key words: Post-Traumatic Stress Disorder, Job Performance, Perceived Job Performance, Afghanistan, Psychological Well-being.
\end{abstract}

\section{Introduction}

Afghanistan has been a war torn country for decades now and has experienced years of war, insecurity, terrorism, floods, earthquakes, issues and challenges that have had a destructive impact on the lives of Afghan people, institutions and organizations. Millions were killed, others were forced to leave the country and the infrastructure and institutions were destroyed. Currently Afghanistan is experiencing a period of transition while terrorist activities are at their peak causing stress to the people and affecting the transition process negatively. One of the main reasons for inefficiency besides corruption in Afghanistan may be the impact of traumatic events.

According to Zeidner et al. (2012) the majority of the worlds 450 million people with mental health problems are in developing countries and (WHO) the majority of them do not have access to treatment. Although the exact number of Afghans with mental health problems has not been identified yet; studies show that families in Afghanistan have lost one or more members

*Corresponding author.

Email: m.naeem00@yahoo.com during the 30 years of war. Studies by national and international organizations such as Care International and practitioners of Human Rights have indicated that a large portion of Afghanistan population (66\%) is affected by Post-Traumatic Stress Disorder PTSD as a result of war and use of weapons; approximately half of Afghans with more than 15 years of age are victims of PTSD.

Post-Traumatic Stress DisorderPTSD is associated with psychological problems and experienced as a result of traumatic event. Basically trauma is a disturbing experience having negative impact on behavior, working potential, interest, motivation, efficiency and productivity of employees which ultimately affects organization and the overall economy (Andersen et al., 1991; Clohessy and Ehlers, 1999). Stresses both internal and external had been ignored for years, internal, i.e. organization and job related stresses and external, i.e. family, society, economy and security that result in traumatic stress (Maes et al., 2001) affecting employees absenteeism and turnover (Blanchard et al., 1996); because they cant concentrate due to the problems they are facing. The same situation can be observed 
in Afghanistan, resulting in traumatic stress arising domestic and professional problems such as mess in work-life balance, low productivity and turnover.

Since 2001, as part of developments in Afghanistan, despite the unstable situation, economic activities have started, billions of dollars have been floating into Afghanistan, countries from across the world have started their aids and thousands of national and international organizations have been established and many national and international private universities have started delivering educational services to the people of Afghanistan, attracting both national and international staff with their attractive salary and benefit packages from across the globe, but yet they forgot to think about the most valuable resource of the organization, i.e. the human resources; hit by war and terrorism, greatly affecting their employees and their productivity.

Hence keeping in mind the past and current situation of Afghanistan it is decided to conduct this study in Kabul. The findings will facilitate giving a clear image of human resources in Afghanistan and suggest possible solution plans to the universities and Ministry of Higher EducationMoHEand meanwhile fulfill the partial requirement of Masters degree. This study aims to investigate the Prevalence of Post-Traumatic Stress Disorder and its impact on Job Satisfaction and Perceived Job Performance of Faculty Members of Private Universities in Kabul.

\section{Literature Review}

\subsection{Post-Traumatic Stress Disorder (PTSD)}

PTSD is a psychological response to seeing, hearing or experiencing an extremely stressing/ traumatic event such as war, physical torture, natural tragedy, accident, loss of someone close (Gilbert et al., 1988) kidnapping, terrorist attacks and other life frightening events (Tucker et al., 1999) resulting in a number of psychological, physiological and psychosomatic problems (Iribarren et al., 2005; Murthy and Lakshminarayana, 2006; Niaz et al., 2006) such as flashbacks, depression, nightmares, regular avoidance of reminders of the event, insomnia, memory related problems, anxiety disorders, and drug abuse, negatively affecting the abilities and performance of the affected individual (Breslau, 2001). Meanwhile, employees who are more exposed to terrorist activities experience more signs of post-traumatic Stress disorder (Hodgins et al., 2001).

Post-traumatic stress disorder was initially found in people who have been through traumatic situation in their lives e.g. war veterans, assault and terrorism victims (Maes et al., 2001) and got prominence after the Vietnam war. The war veterans in different countries especially Vietnam, Iraq, and Afghanistan are experi- encing serious PTSD during and after the war missions. The concentration on PTSD was initially started after the Vietnam war where the focus of the researchers were the ex-army officers who had served in Vietnam war, however less attention was given to general public; since then works regarding general definition, nature, detections, measurement, treatment and management have been done.

Humans in their personal and professional lives go through many different stages, experiences, surprises and events, i.e. joy events and different traumatic events. As human is the most complex and unpredictable animal in nature, it becomes difficult for them to cope up with certain situations and people. They usually face difficulties and problems while adjusting and coping with certain problems, which give birth to posttraumatic stresses, although these stresses can be overcome by taking care of themselves, but sometimes it is difficult which in return gives birth to traumatic stress disorders (Cardena et al., 1991). Experiencing stress after traumatic event is usual and results in some kind of reactions like feeling afraid or having no control over what is happening and think that his/her life or others' lives are in danger. Meanwhile, after experiencing a traumatic event everyone doesnt develop PTSD but very few people do. Though causes of PTSD are not definite, but researchers believe that PTSD may be influenced by the persons personality, some heredity makeup and gravity of an event. Statistics shows that female gender, children in the house, ethnic minority, middle-aged, lower socioeconomic status, pre-existing psychiatric conditions, primary exposure to the event including injury, life-threatening situation, loss, and women with children are more likely to exhibit PTSD (Alexander and Wells, 1991). Men are more likely to experience trauma as a result of accidents, physical assault, combat, disaster, and death or injury; while women are more likely to experience trauma as a result of sexual assault. Meanwhile, children may also develop PTSD having the same symptoms discussed above or other symptoms depending on their age. Their symptoms are more likely to change to those of adults as they grow.

Sometimes direct victims of trauma believe that they or their family members are in danger resulting in severe reaction during the event, such as crying, shaking, vomiting or feeling apart from the surrounding; meanwhile, feeling helplessness during trauma would more likely to develop PTSD. Also, people who are poorly educated, women, young people, previous victims of trauma, people with other mental problem, or having any family member with mental problems, little support from family and friends, and recent loss of a loved one, would more likely to develop PTSD. Culture also plays a role in how one reacts to trauma. People from societies that are open and are willing to talk about problems are more likely to seek help for iden- 
tifying, curing and managing the trauma in time. The survey shows that about $5 \%$ of PTSD cases are as a result of natural disasters, while about $50 \%$ of cases are of rape and survivors of the destruction (Christen et al., 2002; Creamer and Liddle, 2005). Initial studies confirm that factors such as age, family patterns, and initial experience of violence probably play a major role in the development of post- traumatic stress disorder (Corneil et al., 1999; O'brien, 1984; Selley et al., 1991).

Stress is categorized into chronic stress and acute stress. Chronic stress is the conflict associated with balancing ones work, situation or environment with another, i.e. work-family life balance. Chronic stress is ongoing and usually lasts longer. While acute stress is a traumatic event employee faces during organizational restructuring, terrorist attack, and natural disaster, it is shorter in duration but it can be longer than chronic stress disorder. Acute stress is also called a traumatic stress (Alexander and Wells, 1991). Symptoms of acute stress last for less than three months and if the duration exceeds then it is chronic. The causes and symptoms of PTSD are different for different people depending on the conditions victims go through.

Research shows that job related stress has a huge impact on the physical and psychological health of employee but few types of researches have focused on the impact of post-traumatic stress and their effect on the individual employee and organizational outcomes (Andersen et al., 1991; Clohessy and Ehlers, 1999). Recently researchers have started inspecting the effect of PTSD on individual employees and organizational outcomes (Association et al., 1980) and most of the organizations have been focusing on organizational stresses to overcome traumatic events that lead to stress (Blanchard et al., 1996) because studies revealed that organizational stress has a costly and negative impact on the organization and its employees (Epstein et al., 1998; Tjemsland et al., 1998). On the other hand traumatic events in personal life also have a negative impact on employees professional life usually resulting in absenteeism (Maes et al., 2001; McFarlane, 2000). PTSD can be developed as a result of both man-made and natural traumatic events, and employees who work with victims are more likely to develop stress (Weiss, 2002).

The exposure of symptoms differ from person to person (Fox and Lief, 1963; Halpern, 2001) some may experience it for a longer time, while in some cases trauma may become chronic. It usually shows up within three months of the event but sometimes it may take a year, but once the symptoms show up they may go away within six months, so the person should keep track of the symptoms, because it disturbs the normal life of the victim. Literature suggests that factors such as exposure to trauma, degree of loss, fear, history of mental illnesses, etc. increase the risk of PTSD (Niaz et al., 2006). If the above mentioned symptoms exist for more than four weeks, resulting in stress and dis- turbing your domestic and work life, you might have PTSD and would need professional help from a doctor or counselor. Those symptoms fall into four categories; Re-living the event (Re-experiencing symptoms); regular and repeated occurrence of trauma, resulting in flashbacks, repeated painful memories or nightmares, Avoiding situations that remind you of the event; trying to avoid situations or people that remind memories of the traumatic event, Negative changes in beliefs and feelings; thinking may change about oneself and others, not in good mood, lack of interest in routine life and activities which an individual used to enjoy, carelessness and detachment from others; Hyper-arousal, nervous or always on the lookout for danger, become more sensitive and lose temper easily, may face difficulty in concentration alertness, and sleeping (Dweck, 2013; Edmondson et al., 2001). While the three major types of PTSD are: Sudden great damages, events that are natural disaster such as earthquakes, etc. Accidental Suffering such as airplane crashes, deaths and accidents; Human induced disaster like war, kidnapping, robbery, hijack, and murder, etc.

Experts say that causes of mental health illnesses are not limited to war, domestic violence, extreme poverty but lack of access to treatment and rehabilitation also cause mental illnesses and even watching videos of victims or the incident may also develop PTSD which means that Traumatic event does'nt just affect the ones directly involved, but may affect people worldwide. In Afghanistan violence ranges from armed insurgency to family conflict (UK medical journal, The Lancet) and war causing mental health problems to many Afghans (Musadi Nadimee). The war in Vietnam, Iraq, and Afghanistan, and earthquakes in Japan, AJK, KPK and Tsunami have forced the professionals to realize the cost of these disasters which didnt only cause damages to properties, but also resulted in disabilities and loss of lives (Goenjian et al., 1994).

Research indicates higher prevalence of PTSD in females and children as compared to men, because fear dominate their mind and make them suffer longer; while Telles et al. (2009) observed higher prevalence of mental health problems in aged people in Bihar, India. Studies show that PTSD is higher in people of age eighteen and higher in comparison to victims under eighteen and the risk of PTSD as a result of natural events is higher in victims of age 35-54years. Atta (2013) has investigated prevalence of PTSD in the school teachers of 2010 flood affected district, Nowshera; (Wali et al., 2018) have investigated PTSD occurrence in Khyber Agency, and both of them found that nearly all the respondents were victims of PTSD.

Stress and disturbance is usual after a traumatic event and victims get better in time, but if the symptoms last longer than three months the victims are required to seek help before it disturb their personal and professional life. PTSD can be treated access to help 
and coping skills (proper management and treatment) can effectively control it to avoid the interference of the symptoms in everyday activities, work and relationships but it doesn't always guarantee recovery. There are two ways of treatment, e.g. psychotherapy (counseling) and medication. The nature of treatment depends on the intensity and nature of the trauma, sometimes both the psychotherapy and medication are combined, while in some cases they are used separately. In psychotherapy (counseling) the patient meets with a therapist and goes through certain psychotherapies such as The Cognitive Processing Therapy, involves learning skills to understand how trauma changed victims thoughts and feelings; Prolonged Exposure Therapy is where victim are asked to talk about trauma repeatedly until memories are no longer disturbing and going to places that are safe, but avoided because they were related to the trauma and the Eye Movement Desensitization and Reprocessing involves focusing on sounds or hand movement while talking about the trauma. Medication can also be effective for PTSD treatment where different types of medicines are used for depression and nightmares

Post-Traumatic stress is actually an environmental issue in or outside the workplace negatively effecting employee and organization (Maes et al., 2001), and urging employees to leave the organization due to the situation they are facing (Blanchard et al., 1996). These factors caught the attention of organizations toward employees with PTSD and forced them to work with researchers on policies to overcome and limit the effect of stressors and traumatic events employees face in their workplace (Epstein et al., 1998).

\subsection{Job Satisfaction}

Satisfaction is the achievement of desires (Thorndike and Barnhart, 1988). Thus a person is satisfied when his/her needs or desires are fulfilled. Theories of satisfaction have been recommended by Maslow (1954) and Herzberg and Mausner (1959). According to Maslow, a person is satisfied when his/her five basic needs such as physiological, safety, affiliation, selfesteem and self-actualization needs are accomplished; whereas Herzberg had introduced motivation-hygiene theory that focuses on two factors which determine a persons satisfaction. First the factors that cause job satisfaction in the workplace and others that cause dissatisfaction. Motivators are used for positive satisfaction through internal factors such as recognition, achievement or personal growth; while in absence of hygiene factors such as company policies, supervisory practices, wages dissatisfaction arises (Herzberg and Mausner, 1959).

Job satisfaction refers to a complete set of positive feelings linked to the job; increasing the positive attitude of employee toward his/her job, if an individual is satisfied from his job, he may show interest in his job and fulfill his responsibilities efficiently and dissatisfaction about the job may cause stress, physical complaints and interpersonal conflict to an individual which may affect his/her performance and the performance of organization as a whole. Nelson (2006) valued employee satisfaction because Dissatisfaction adversely affects the desire to do the job and dissatisfied employees are less dedicated to the company which in turn affects their performance and the performance of the entire organization.

Research shows a direct relation between Job satisfaction, efficiency and individual comfort. Many definitions have been suggested by different people; Locke (1976) described job satisfaction as an enjoyable state that results from the positive assessment of job experiences and achievements in work. It is actually a positive change in behavior that indicates how employees feel about their job and focus on direct response to several factors in the workplace (Mowday et al., 1982); while Weiss (2002) called it an attitude of having an obvious difference among beliefs, behaviors and emotions which shape cognitive evaluation. Job satisfaction plays a vital role in an organization, because it is linked to the efficiency in job (Bazerman et al., 1998).

A variety of factors such as the nature of relationship with the subordinates, working environment, level of achievements in work, determine job satisfaction. There are certain factors that affect the level of satisfaction; organization identification is one of the factors that influence the level of employees satisfaction. The higher the organizational identification is, the more the job satisfaction (Brewer, 1994). An individuals capability of fulfilling given tasks, communication, the behavior of the top management and self interest in the workplace which is linked with pay, working hours and benefits, are other factors that may enhance Job satisfaction. Meanwhile, breach of contract may also cause dissatisfaction Wanous (1973); because the difference between what is predicted or promised and what is obtained can be a key factor of dissatisfaction and can decrease satisfaction of employees (Pieterse, 2015). When mutual agreement made between the employee and company is not fulfilled, employee may be dissatisfied resulting in absenteeism and a higher rate of turnover (Griffeth et al., 2000; Hacket, 1989). Dissatisfaction may result in delivering low quality of services, destructive rumors, robbery and destruction of organization asset, which is costly for the organization (Spector, 1997). On the other hand anxiety, disrupted sleep pattern, exhaustion, depressive disorders are usual in dissatisfied employees (Frese, 1985; O'brien and Kabanoff, 1979; Spector, 1997) which affects employees emotions and welfare. Job satisfaction is based on intrinsic and extrinsic factors, where intrinsic Factors include recognition, advancement, responsibilities and achievements; extrinsic factors include salary, work condition, regu- 
lation and administrative policies Griffeth et al. (2000). Job satisfaction in teachers differs from individual to individual. Meanwhile, the factors affecting their job satisfaction mostly include working conditions, balance of workload, self-efficacy, management attitude, students behavior and salary (Griffeth et al., 2000).

The theories established to elaborate the factors affecting job satisfaction are broadly classified into two perspectives: process theories and content theories. Process theories deal with the "process" of how motivation occurs. It includes variables like values, expectations, desires, and insights and how there variables relate to seek job satisfaction. Content theories deal in "what" motivates people and are usually linked with individual needs and goals. The two leading theories in this regard are need hierarchy theory by Maslow (1954) and Motivation-Hygiene theory by Herzberg and Mausner (1959), which is also called two factor theories (Manisera et al., 2005).

\subsection{Perceived Job Performance}

Job performance is under the focus of industrial and organizational psychology, and human resources management because performance plays important role in success and achievements of organizational goals. According Campbell, job performance is a micro level variable linked with an individual as compared to organizational performance. Performance is a behavior an individual shows and deals with how an individual perform in achieving the goals. According to Laitinen (2002) performance is the ability of something or someone to produce results against a pre-determined target. While Perceived job performance is the perception of one's self about something he/she does. Researchers agree that effort, compensation, quality of supervision and clarity of job responsibility are the common predecessors of job satisfaction and job performance (Christen et al., 2006).

PTSD may affect workers and also influence the work environment (McFarlane, 2000). Workers with PTSD may go into conflict with peers, subordinates and management. Meanwhile, Riaz et al. (2016) have investigated PTSD prevalence and its impact on the performance of small businesses in Peshawar and Kohat and found that the prevalence of PTSD in small business owners affected their businesses and the performance of business owner depends on his cognitive abilities, psychological wellbeing and health condition. So we can conclude that PTSD affects the performance of owner negatively, affecting the overall performance of the business, because the performance of business is linked to its leadership and management performance. Shahzad et al. (2008) examined the relationship between three HR practices (compensation, promotion and performance evaluation) and perceived employee performance of university teachers in Pakistan. They found that positive relationship between compensation and promotion practices and employee perceived performance.

In the light of above review of literature, following hypotheses are put forth:

$H^{1}$ : Post-Traumatic Stress Disorder effects job satisfaction.

$H^{2}$ : Post-Traumatic Stress Disorder has a negative impact on employees perceived job performance.

\section{Methodology}

\subsection{Population and Sampling}

Current study is the correlational study and the primary focus of the current research is to investigate the prevalence of PTSD and its impact on job satisfaction and perceived job performance in faculty members of private universities in Kabul, the population for this research comprises of faculty members of private universities in Kabul, who will serve as the respondents for this research. Data for this research is collected from six universities of Kabul (see table 3.1).

The sample is drawn using twofold stratified sampling techniques. 6 out of the 49 private Higher Education InstitutesHEIs were chosen in first stage. In the next stage proportionate sample of 200 faculty members was drawn from these six HEIs. Data were collected through self-administered questionnaire in person from the faculty members of private universities in Kabul city. Heads of Departments of each university were approached. Upon approval, questionnaires were administered. A total of 180 questionnaires were distributed among respondents. 150 were returned (83.34\% response rate). After checking, it was found that 24 questionnaires were not filled properly which means that a total of 126 questionnaires were found analysis ready.

A total of 126 questionnaires were analyzed. $21.43 \%(n=27)$ of the respondents were bachelors, $56.35 \%(n=71)$ were masters, $18.25 \%(n=23)$ were MPhil/MS while the remaining $3.97 \%(n=5)$ of the respondents were PhD scholars. Majority of the respondents, $72.22 \%(n=91)$ were Afghan nationals, while the remaining 27.78(n=35) were Pakistani. Ethnically majority of the respondents $57.94 \%(n=73)$ were Pakhtun while Tajik counted for $29.37 \%(n=37)$, and Hazara respondents counted for $8.73 \%(n=11)$ and the rest of the respondents; Panjabi, Hindko Nooristani, and Qazalbash counted for $3.96 \%(n=4)$. 


\section{Measures}

\subsection{Post-Traumatic Stress DisorderPTSD}

PTSD Check List for Civilian (PCL-C) a 17 items construct on a Likert scale ( 1 for not at all to 5 for extremely) is used (Weathers et al., 1994). The score of respondents on PCL-C ranges from 17 to 85 . Cronbach Alpha was 0.844 .

\subsubsection{Job Satisfaction}

A five Likert items (five points) measure developed by Babin and Boles (1998) was used to measure job satisfaction, with the Cronbach Alpha value at .883.

\subsubsection{Perceived Job Performance}

The perceived Job Performance Scale (JPS) was developed by Brown and Leigh (1996). It consists of 10 items divided into time commitment and work intensity each consist of five items with a Likert rating scale of 5 points, ranging from strongly disagree to strongly agree. Its Cronbach Alpha was 0.766

\section{Results}

\subsection{PTSD Prevalence}

Version four (DSM-IV) of Diagnostic and Statistical Manual of Mental Diseases has suggested two criteria (National-Center-for-PTSD, 2014) for prevalence of PTSD, i.e. there be at least one $\mathrm{B}$ (a little bit) response in items1-5, three $C$ (moderate) responses in items 6-12, and at least two D (quite a bit) responses in items1317 , and/or a threshold score may also be used. While checking the questionnaires it was found that all respondents met the first criteria. For second criterion, a threshold score of 38 is used which means that whose total PCL score is greater than 38, they shall be considered victim of PTSD. This threshold score is used as standard in this study because Niaz et al. (2006) in NWFP and by Riaz et al. (2016) in frontier region of Peshawar and Kohat used it and it is known that Khyber Pakhtunkhwa and Afghanistan share their social and cultural values and have been hit by the ongoing war on terror. Out of 126 questionnaires, 82 respondents which count for $65.08 \%$ of the total samples are victims of PTSD while other 44 respondents which actually counts for $34.92 \%$ of the total samples indicates Non-PTSD victims.

\subsection{Data Analysis and Hypo-testing}

To check the first hypothesis Post traumatic stress has a negative impact on job satisfaction linear regression was applied. R2 value was 0.529 with $\mathrm{F}(126.1)=$ $166.472(\mathrm{p}<.000)$ with $\beta$ PTSD of -.540 , which supports the fact that PTSD has a significant negative impact on employee Job satisfaction. Thus H1 is supported and accepted.

Similarly, PTSD was regressed against perceived job performance. The regression results showed R2 value was 0.515 with $F(12.61)=157.062(p<.000)$ with $\beta$ PTSD of -.297 which supports the fact that PTSD has significant negative impact on perceived employee job performance. Thus $\mathrm{H} 2$ is also supported and accepted.

\section{Discussion and Conclusion}

This research was conducted to examine the prevalence of post-traumatic stress disorder and its impact on job satisfaction and perceived job performance of faculty members of private universities in Kabul, Afghanistan that have been affected by decades of war and the ongoing war on terror. The study found that faculty members of private universities were victims of PTSD and PTSD negatively affects employees job satisfaction and perceived job performance.

While studies show that job related stress has a huge impact on physical and mental health of employee, few researches have been done to investigate the impact of post- traumatic stress on individual employees and organizational outcomes (Andersen et al., 1991; Clohessy and Ehlers, 1999), but now researchers are studying it (Association et al., 1980) and most of them have focused on organizational stresses to overcome disturbing events that lead to stress (Blanchard et al., 1996) because studies disclose that extra organizational stress has a costly and negative impact on organization and its employees (Epstein et al., 1998; Tjemsland et al., 1998). Exposure to PTSD may affect workers and also influence the work environment (McFarlane and Bryant, 2007) workers with PTSD may go into conflict with peers, subordinates and management that may in return affect their mental wellbeing in many ways. Meanwhile, PTSD in small business owners badly affected their businesses and the performance of business owner depends on his cognitive abilities, psychological wellbeing and health condition (Riaz et al., 2016). So we can conclude that PTSD can affect the performance of owner negatively which can affect the overall performance of the business because the performance of any business is linked to its leadership and management performance.

This study is the first one in its nature in Afghanistan, was conducted keeping in mind the past and current situation of Afghanistan, to give a clear image of human resources and suggest possible solution plans to the ministry of higher education and universities to come up with certain policies, procedures and strategies to overcome stresses and let the employees work in a safe environment with peaceful mind. Analysis of this study reveals that $65.08 \%$ of the respondents 
are victims of PTSD and other $34.92 \%$ are non-victims and support a significant relation between PTSD and job satisfaction and perceived job performance. So we can conclude that PTSD has a significant impact on job satisfaction and perceived job performance of faculty members of private universities in Kabul, Afghanistan.

\subsection{Future directions}

There are some suggestions for future researches; this research is limited to the private universities in Kabul, if the researcher expands the area of sampling to other provinces and involves public sector universities that may get different result. This study is limited to samples from only 6 private universities in Kabul city and had data from a limited number of 126 respondents, if future researchers incorporate larger sample based on gender, age, culture and nationality and involves mediators such as Self Efficacy into studying the impact of PTSD on Job Satisfaction and Perceived Job Performance that may get different results and measure different levels of PTSD and its impact on job satisfaction and perceived job performance.

Controlling the impact of PTSD is not always easy and cannot be done without actually controlling the prevalence of PTSD. Once the prevalence of PTSD is controlled then it is possible to decrease and overcome its impact on individuals. The major institutions that can play role in controlling the prevalence of PTSD and its impact on individuals are government, security agencies and MoHE who are the major policy makers in Afghanistan and then the universities. The study recommends the policy makers to work on plans for rehabilitation of affected ones and also provides some suggestions that would help in lowering its impact. On the government side; no private higher education institute should be let free. A regulatory and supervisory committee should be established to control and monitor the institutes and meanwhile regulations must be updated on regular basis as required. A collaboration between MoHE and the security agencies are needed, first and the most important is the location of universities and their guest houses; government should work on plans regarding provision of lands and buildings to universities in a relatively safe and calm areas of the city which on one hand would help overcome the level of PTSD and on another hand will provide a relatively calm place for both the faculty members and the students away from crowd and insecurity. Secondly, they must work on making plans regarding provision of security to the universities and their personnel in and outside the educational institutes because education is the backbone of a country and directs a country towards development.

While on the universities side, first of all the environment of educational institutes should be friendly and free of any kind of discrimination, especially gen- der discrimination. Universities must brief their employees, especially non-Afghans about situations, especially security situations in Afghanistan upon their arrival.

Secondly, work together with government institutions for acquiring location in the safe and calm areas of the city and work on plans regarding security measures in and outside the university.

Thirdly, effective programs must be implemented either by MoHE or the institutions themselves to fight against violence. Faculties' staff must be trained and regular trainings, seminars and briefings to their employees would be helpful in giving them information about the situation in Afghanistan and equipping them with several self-care and defense actions and techniques to protect themselves in unwanted situations that lead to stress.

And finally, universities must hire psychologist and psychological consultants who will regularly check the psychological wellbeing of employees and help them in overcoming and meanwhile work with employees and train them for self-care and safety in groups and individually.

\section{References}

Alexander, D. A. and Wells, A. (1991). Reactions of police officers to body-handling after a major disaster a beforeand-after comparison. The British Journal of Psychiatry, 159(4):547-555.

Andersen, H. S., Christensen, A. K., and Petersen, G. O. (1991). Post-traumatic stress reactions amongst rescue workers after a major rail accident. Anxiety research, 4(3):245-251.

Association, A. P. et al. (1980). Diagnostic and statistical manual of mental disorders; dsm-iii. Washington DC.

Babin, B. J. and Boles, J. S. (1998). Employee behavior in a service environment: A model and test of potential differences between men and women. The Journal of Marketing, pages 77-91.

Bazerman, M. H., Tenbrunsel, A. E., and Wade-Benzoni, K. (1998). Negotiating with yourself and losing: Making decisions with competing internal preferences. Academy of Management Review, 23(2):225-241.

Blanchard, E. B., Hickling, E. J., Barton, K. A., Taylor, A. E., Loos, W. R., and Jones-Alexander, J. (1996). One-year prospective follow-up of motor vehicle accident victims. Behaviour research and therapy, 34(10):775-786.

Breslau, N. (2001). Outcomes of posttraumatic stress disorder. The Journal of clinical psychiatry.

Brewer, A. (1994). The responsive employee. Allen and Urwin Pub. Sydney, Australia. 
Brown, S. P. and Leigh, T. W. (1996). A new look at psychological climate and its relationship to job involvement, effort, and performance. Journal of applied psychology, 81(4):358.

Cardena, E., Classen, C., and Spiegel, D. (1991). Stanford acute stress reaction questionnaire. Department of Psychiatry and Behavioural Sciences. Stanford Medical School.

Christen, H. T., Maniscalco, P. M., and Christian, H. T. (2002). Mass casualty and high-impact incidents: an operations guide. Brady.

Christen, M., Iyer, G., and Soberman, D. (2006). Job satisfaction, job performance, and effort: A reexamination using agency theory. Journal of Marketing, 70(1):137-150.

Clohessy, S. and Ehlers, A. (1999). Ptsd symptoms, response to intrusive memories and coping in ambulance service workers. British journal of clinical psychology, 38(3):251-265.

Corneil, W., Beaton, R., Murphy, S., Johnson, C., and Pike, K. (1999). Exposure to traumatic incidents and prevalence of posttraumatic stress symptomatology in urban firefighters in two countries. Journal of occupational health psychology, $4(2): 131$

Creamer, T. L. and Liddle, B. J. (2005). Secondary traumatic stress among disaster mental health workers responding to the september 11 attacks. Journal of Traumatic Stress: Official Publication of The International Society for Traumatic Stress Studies, 18(1):89-96.

Dweck, C. S. (2013). Self-theories: Their role in motivation, personality, and development. Psychology press.

Edmondson, A. C., Bohmer, R. M., and Pisano, G. P. (2001). Disrupted routines: Team learning and new technology implementation in hospitals. Administrative Science Quarterly, 46(4):685-716.

Epstein, J. N., Saunders, B. E., Kilpatrick, D. G., and Resnick, H. S. (1998). Ptsd as a mediator between childhood rape and alcohol use in adult women. Child Abuse E Neglect, 22(3):223-234.

Fox, R. and Lief, H. (1963). Training for detached concern.. The Psychological Basis of Medical Practice. New York, NY: Harper \& Row, pages 12-35.

Frese, M. (1985). Stress at work and psychosomatic complaints: a causal interpretation. Journal of applied psychology, $70(2): 314$.

Gilbert, D. T., Pelham, B. W., and Krull, D. S. (1988). On cognitive busyness: When person perceivers meet persons perceived. Journal of personality and social psychology, 54(5):733.

Goenjian, A. K., Najarian, L. M., Pynoos, R. S., Steinberg, A. M., et al. (1994). Posttraumatic stress disorder in elderly and younger adults after the 1988 earthquake in armenia. The American Journal of Psychiatry, 151(6):895.
Griffeth, R. W., Hom, P. W., and Gaertner, S. (2000). A meta-analysis of antecedents and correlates of employee turnover: Update, moderator tests, and research implications for the next millennium. Journal of management, 26(3):463-488.

Hacket, R. D. (1989). Work attitudes and employee absenteeism: A synthesis of the literature. Journal of occupational psychology, 62(3):235-248.

Halpern, J. (2001). From detached concern to empathy: humanizing medical practice. Oxford University Press.

Herzberg, F. M. and Mausner, B. (1959). B. \& snyderman, b.(1959). The motivation to work, 2.

Hodgins, G. A., Creamer, M., and Bell, R. (2001). Risk factors for posttrauma reactions in police officers: A longitudinal study. The Journal of nervous and mental disease, 189(8):541547.

Iribarren, J., Prolo, P., Neagos, N., and Chiappelli, F. (2005). Post-traumatic stress disorder: evidence-based research for the third millennium. Evidence-Based Complementary and Alternative Medicine, 2(4):503-512.

Laitinen, E. K. (2002). A dynamic performance measurement system: evidence from small finnish technology companies. Scandinavian journal of management, 18(1):65-99.

Locke, E. A. (1976). The nature and causes of job satisfaction. Handbook of industrial and organizational psychology.

Maes, M., Mylle, J., Delmeire, L., and Janca, A. (2001). Preand post-disaster negative life events in relation to the incidence and severity of post-traumatic stress disorder. Psychiatry Research, 105(1-2):1-12.

Manisera, M., Dusseldorp, E., and Van Der Kooij, A. J. (2005). Component structure of job satisfaction based on herzbergs theory. Rapporti di Ricerca del Dipartimento di Metodi Quantitativi, Brescia University, Working paper, 253.

Maslow, A. H. (1954). The instinctoid nature of basic needs 1 . Journal of Personality, 22(3):326-347.

McFarlane, A. C. (2000). Posttraumatic stress disorder: A model of the longitudinal course and the role of the risk factors. The Journal of clinical psychiatry.

McFarlane, A. C. and Bryant, R. A. (2007). Post-traumatic stress disorder in occupational settings: anticipating and managing the risk. Occupational Medicine, 57(6):404-410.

Mowday, R. T., Porter, L. W., and Steers, R. M. (1982). Employee-organization linkage. The psychology of commitment absenteism, and turn over_Academic Press Inc. London.

Murthy, R. S. and Lakshminarayana, R. (2006). Mental health consequences of war: a brief review of research findings. World psychiatry, 5(1):25.

Nelson, N. (2006). A little appreciation can go a long way toward employee job satisfaction. Employment Relations Today, 33(1):19-26. 
Niaz, U., Hassan, S., Hassan, M., Hussain, H., and Ahad, S. (2006). Prevalence of post-traumatic stress disorder and comorbid depression in earthquake survivors in nwfp, pakistan: a preliminary study. Journal of Pakistan Psychiatric Society, 3(July-December Number 2):98.

O'brien, G. E. (1984). Reciprocal effects between locus of control and job attributes. Australian Journal of Psychology, 36(1):57-74.

O'brien, G. E. and Kabanoff, B. (1979). Comparison of unemployed and employed workers on work values, locus of control and health variables. Australian Psychologist, 14(2):143-154.

Pieterse, D. (2015). Childhood maltreatment and educational outcomes: Evidence from south africa. Health economics, 24(7):876-894.

Riaz, M. K., Jamal, W., and Jan, F. A. (2016). I, we and you: A study of relationship of individualism-collectivism and conflict management styles.

Selley, M., Lacey, M., Bartlett, M., Copeland, C., and Ardlie, N. (1991). Content of significant amounts of a cytotoxic end-product of lipid peroxidation in human semen. Journal of reproduction and fertility, 92(2):291-298.

Shahzad, K., Bashir, S., and Ramay, M. I. (2008). Impact of hr practices on perceived performance of university teachers in pakistan. International review of business research papers, 4(2):302-315.

Spector, P. E. (1997). Job satisfaction: Application, assessment, causes, and consequences, volume 3. Sage publications.

Telles, S., Singh, N., and Joshi, M. (2009). Risk of posttraumatic stress disorder and depression in survivors of the floods in bihar, india. Indian Journal of Medical Sciences, 63(8):330-330.

Thorndike, E. L. and Barnhart, C. L. (1988). Scott, Foresman advanced dictionary. Scott Foresman \& Co.

Tjemsland, L., Søreide, J. A., and Malt, U. F. (1998). Posttraumatic distress symptoms in operable breast cancer iii. Breast Cancer Research and Treatment, 47(2):141-151.

Tucker, P., Pfefferbaum, B., Nixon, S. J., and Foy, D. W. (1999). Trauma and recovery among adults highly exposed to a community disaster. Psychiatric Annals, 29(2):78-83.

Wali, N., Chen, W., Rawal, L. B., Amanullah, A., and Renzaho, A. M. (2018). Integrating human rights approaches into public health practices and policies to address health needs amongst rohingya refugees in bangladesh: a systematic review and meta-ethnographic analysis. Archives of Public Health, 76(1):59.

Wanous, J. P. (1973). Effects of a realistic job preview on job acceptance, job attitudes, and job survival. Journal of applied psychology, 58(3):327.

Weathers, F. W., Litz, B. T., Herman, D., Huska, J., and Keane, T. (1994). The ptsd checklist-civilian version (pcl-c). Boston, MA: National Center for PTSD.

Weiss, H. M. (2002). Deconstructing job satisfaction: Separating evaluations, beliefs and affective experiences. Human resource management review, 12(2):173-194.

Zeidner, M., Matthews, G., and Roberts, R. D. (2012). What we know about emotional intelligence: How it affects learning, work, relationships, and our mental health. MIT press. 